\title{
Modes of Supply for U.S. Exports of Services
}

\author{
Elisabeth Christen \\ Austrian Institute of Economic Research \\ Joseph Francois \\ University of Bern and CEPR
}

September 22, 2015

\begin{abstract}
We examine the choice of modes of delivery in services based on U.S. data, including both cross border exports and sales through foreign affiliates. We focus on characteristics of destination markets and how this impacts on mode choice. We find that market size, distance, and policy all play a role in where firms establish, and in how many firms enter. The importance of sales through affiliates relative to total foreign sales also depends on factors like market size, geographic and economic distance, and the policy regime in place. Precisely how important these factors are depends on the sector in question.
\end{abstract}

Keywords: International Trade in Services, Modes of Supply, FDI, Foreign Affiliates Trade, GATS

JEL codes: F10, F14, F23, L80

${ }^{*}$ We would like to thank Eddy Bekkers, Bernard Hoekman, and participants at several workshops for helpful comments and suggestions. Address for correspondence: Elisabeth Christen, Austrian Institute of Economic Research, Arsenal, Object 20, 1030 Vienna, Austria. Email: Elisabeth.Christen@wifo.ac.at. 


\section{Introduction}

Delivery of services often has an element of "jointness in production" in the sense that complementary inputs - including other services - are needed to allow effective exchange of (trade in) a service to occur. While this can also be true for goods - various intermediate inputs are needed to produce a unit of final output - jointness in production for services goes beyond this in the sense that often the buyer or consumer is more directly part of the production process in the case of services. Where there is a need for proximity in exchange, factors like distance place a cost burden on certain forms of services delivery. This is the "proximity burden," and addressing it can involve real resource costs. As such, while it is different from physical distance costs linked to transport of goods, the proximity burden means that distance can be expected to play a role in service transactions. Indeed this is recognised implicitly in the policy community, where the cross-border and local presence (or commercial establishment) components of international service transactions are reflected in a typology of transactions that framed the construction of the General Agreement on Trade in services (GATS). Because FDI can facilitate trade where imported services are ultimately delivered through foreign affiliates, restrictions on FDI can manifest themselves, econometrically, as effective determinants of cross-border trade as well (Francois and Hoekman, 2010).

The main focus of this paper is examination of the choice of modes of delivery in services based on data on U.S. services trade, including both cross border exports and production and sales through foreign affiliates of U.S. firms. In this sense we fit into the recent stream of research building on national data on services trade, such as Breinlich and Criscuolo (2011) with UK data and Kelle (2013) with German data. However, while recent literature has focused on the characteristics of exporting firms, we instead focus on the characteristics of destination markets and how this impacts on firm decisions on mode of delivery 
and on whether to establish affiliates in given destination markets. We find that market size, distance, and policy all play a role in where U.S. firms establish, and in how many U.S. firms choose to enter and operate locally. The importance of sales through affiliates relative to total foreign sales also depends on factors like market size, geographic and economic distance, and the policy regime in place. Precisely how important these factors are depends on the sector in question.

The paper is organised as follows. In Section 2 we focus on stylised facts regarding trade and investment in services. This helps frame and motivate the empirical exercise that follows in Sections 3 and 4. Our data on foreign affiliate sales, cross-border sales and the number of U.S. parents with foreign affiliates come from the Bureau of Economic Analysis (BEA). Our empirical approach examines first the location choice of foreign affiliates and in a second step tries to answer the question of how foreign markets are served. In the latter, we focus on the relative importance of direct cross-border trade and indirect sales through local establishments. While Section 3 is focused on services, for comparison, a contrasting study on the choice of modes in manufacturing sectors is presented in Section 4. We offer a brief summary and concluding remarks in Section 5.

\section{$2 \quad$ Stylized facts}

In this section we develop a set of stylised facts based on the pattern of U.S. cross-border exports and sales of services through affiliates. This includes choice of mode of supply (cross-border vs. establishment), and overall patterns of concentration for the population of U.S. affiliates. These help us frame the empirical exercise that then follows in Sections 3 and 4.

The WTO distinguishes four different modes of supply for services ${ }^{1}$, which frame the basic structure of the General Agreement of Trade in Services (GATS):

\footnotetext{
${ }^{1}$ This typology for modes was developed by Sampson and Snape (1985) and was largely adopted as a framework for the GATS.
} 
- Mode 1 - cross-border trade: when suppliers of services in one country supply services to consumers in another country without either supplier or consumer moving into the territory of the other

- Mode 2 - consumption abroad: process by which a consumer resident in one country moves to another country to obtain a service

- Mode 3 - commercial presence: enterprises in an economy supply services internationally through the activities of their foreign affiliates abroad

- Mode 4-movement of natural persons: process by which an individual moves to the country of the consumer in order to provide a service.

Multinationals are obviously important for Mode 3 trade. They are also important for Mode 4 (which includes movement of technical personnel), and Mode 1 (as MNEs also engage in direct trade between parent to affiliate). Sales by U.S. affiliates (foreign affiliate trade) accounted for 68.2 percent or $\$ 1,293$ billion of the $\$ 1,948$ billion in combined U.S. cross-border exports and foreign affiliate sales in 2012. This share has risen consistently over the last decade. In addition, of the share of total overseas sales that comes from direct crossborder exports, a substantial portion (27.7 percent in 2012) also goes through affiliates (either U.S. parents to their affiliates, or foreign affiliates in the U.S. to their parents), a share that has held steady for last decade. For "other business service" exports in 2012, a full 60 percent was sold through affiliates (Grim and Krishnan, 2014), with substantial variation with this category.

In addition to the overall importance of establishment, the general pattern in services in terms of firm population is one of concentration, with large firms playing a dominant role both domestically and abroad. ${ }^{2}$ From the BEA MNE

\footnotetext{
${ }^{2}$ Domestically, individual service sectors are typically characterised by a handful of firms representing a relatively large share of the market. This point can be lost when looking at the full population of firms across all service sectors collectively. However, when one focuses on individual sectors, the importance of large firms in the services landscape is striking. For example, in the United States, the largest 4 software publishers accounted for 38.9 percent of revenues in 2007, the 8 largest commercial banking firms accounted for 40 percent of revenues,
} 
benchmark surveys ${ }^{3}$ we see a clear pattern of concentration for foreign affiliates of U.S. parent service companies. Only a limited number of U.S. parents decide to go abroad by establishing a foreign affiliate in a given destination country, whether in goods or services. On a global level 2,451 U.S. parents had at least one affiliate abroad in the year 2004. If we break down the aggregated industry number by specific sectors we observe a pattern of high concentration within some sectors, not as many parents are present in each combination of sector and destination. For instance, 49 U.S. parents were present abroad in the depository-banking sector, where 20 of these parents operated a local presence component in the UK, 15 in Canada, 11 in Germany and Switzerland and 1 in Denmark. In the professional, scientific and technical service sector 367 parents had at least one affiliate in 2004, with 210 in the UK but only 11 in Greece. The heterogeneous pattern across countries does not only arise in specific service sectors, but also manufacturing sectors. In transportation equipment there were 63 affiliates operating in Canada, 53 in Mexico, 51 in Germany, and 8 in Austria. For affiliates in services, basically the pattern for the U.S. is one of even greater concentration than in the domestic market. Indeed, the importance of larger firms, limited competition, and variations in oligopoly behaviour characterise service industries from banking to telecommunications and transport for a broader range of countries (Francois and Hoekman, 2010) than the U.S. case we examine here.

\footnotetext{
4 firms accounted for 44.9 percent of wholesale trade in motor vehicle parts and supplies, 4 firms accounted for 53.2 percent of air freight transport, and 4 firms accounted for 43.2 percent of inland water transport. With the exception of banking, in each case listed the top four firms accounted for roughly 10 percent each, on average, of total sector revenue. There are sectors where the combined market shares of the top firms are relatively small - including mortgage brokers and new car dealerships- but this is the exception and not the rule. Overall, when one moves from "total services" to more specific sectors, a pattern emerges where the top 4 to 8 firms hold, on average, between roughly 7 and 10 percent of the U.S. market each. It is also the case that on an establishment basis, the establishments belonging to the larger firms are also larger on a revenue basis. For example, in the software industry, the U.S. Department of Commerce reports 8,275 establishments for 2007. The top four firms had 300 of these establishments between them or 3.6 percent of the total, yet accounted for 38.9 percent of revenues. (Data based on U.S. Census Bureau, 2007 Economic Census.)

${ }^{3}$ Bureau of Economic Analysis: U.S. Direct Investment Abroad, 2004 Benchmark Survey, Final results. http://www. bea.gov/international/usdia2004f.html
} 


\section{Deconstructing Patterns of Trade in Services}

We now turn to an econometric analysis of market entry modes employed by U.S. service firms. To deconstruct the determinants behind the pattern across sectors and countries, in this section we will examine the impact of several factors, including distance and market size, on the number of U.S. parents engaging in FDI (establishment of affiliates). While distance is important in models with both monopolistic competition and oligopoly-based versions of firm heterogeneity, market size as a determinant of the number of affiliates can help distinguish oligopoly (large firm) settings from large group ones (Melitz, 2003; Helpman et al., 2004; Christen and Francois, 2010; Bekkers and Francois, 2013). We also examine the relative importance of direct and establishment-based trade.

In order to give a better understanding of the location of affiliates as well as the interactions between various modes we focus on the linkages between crossborder trade and local sales of services through affiliates at a sectoral level distinguishing between 13 major service categories. The choice of the estimating framework (and so the questions we focus on) is guided by the stylised facts described in Section 2. Our empirical approach is divided into two parts, a location choice setup and a choice of modes model. First, we start by examining the determinants of serving the foreign market through an affiliate by investigating the number of U.S. parents that have an affiliate in a given destination country. We take account of the fact that this dependent variable is discrete and might be characterised by overdispersion. Therefore, we follow Cameron and Trivedi (1986) and Long (1997) and apply a Poisson model as well as a Negative binomial regression model. Second, we explore the relationship between cross-border and FDI based modes by employing GLM models and seemingly unrelated equations. In order to avoid simultaneity problems between affiliate activity and cross-border trade we use shares of affiliate sales and cross-border 
sales in total foreign sales as dependent variables, following Brainard (1993, 1997). In order to identify whether motives for investing abroad are similar between manufacturing and service sectors, we provide a similar analysis for manufacturing sectors and compare our results found for service sectors to the findings for manufacturing. Our empirical results provide insight into sectorlevel variation in modes of entry (foreign affiliate sales and cross-border) that we will discuss in detail below.

\subsection{Data}

The data are drawn from different sources. Bilateral data on foreign affiliate sales, cross-border sales and the number of U.S. parents with foreign affiliates come from the Bureau of Economic Analysis (BEA). Cross-border transactions include both affiliated and unaffiliated transactions between U.S. companies and foreign residents. Affiliated cross-border trade indicates intra-firm trade within multinational companies and consists of trade between U.S. parent companies and their foreign affiliates and transactions between U.S. affiliates and their foreign parent groups. To capture Mode 1 transactions we only make use of direct cross-border trade. In order to describe Mode 3, commercial presence, we make use of U.S. Foreign Affiliates Trade Statistics (FATS) published by BEA, which are drawn from benchmark and annual sample surveys of U.S. direct investment abroad. By using the FATS data we gather information on sales of services by majority-owned foreign affiliates of U.S. parents, disaggregated by country and industry of the affiliate. The final dataset comprises information on bilateral U.S. trade and foreign affiliate sales for 10 partner countries over the years 1996 to 2007. Data on number of affiliates are for a single year, 2004, based on the BEA benchmark survey. ${ }^{4}$ Data on foreign affiliate sales in

\footnotetext{
${ }^{4}$ The partner countries include Australia, Brazil, Canada, France, Germany, Japan, Mexico, The Netherlands, Switzerland and the United Kingdom, which are the largest services trading partners of the United States.
} 
manufacturing sectors are also taken from BEA. Additionally, trade data for total manufacturing and seven sub-sectors are drawn from the WITS database.

To identify the determinants of entry modes we use several explanatory variables suggested by the recent theoretical and empirical literature. The size of the host country markets is captured through GDP (measured in current U.S. dollars). According to previous literature, market size is expected to have a positive impact on services trade and foreign affiliate sales. GDP, GDP per capita (measured in constant 2000 U.S. dollars) and population data are taken from the World Development Indicators database. Next, to reflect the proximity burden, we include geographic distance ${ }^{5}$ between the United States and the respective partner countries as a proxy for transportation costs (variable distance costs). Hence, there can be a positive coefficient on geographic distance when local establishment sales and cross-border trade act as substitutes, since variable distance cost make cross-border trade more expensive in this case with increasing distance, so that affiliates become a cheaper option. However, there may also be selection effects with distance. On net therefore this is an empirical question. In order to capture some cultural influences we include a language dummy, which indicates if home and host country share a common language familiarity and generally share the same cultural heritage. Since a common language plays an important role in services trade we expect a positive coefficient on language, fostering the establishment of affiliates in the host market to a greater extent than cross-border trade. Geographic distance, together with data on cultural familiarity, is taken from Mayer and Zignago (2011) .

All determinants of affiliate activity described so far, such as market size, geographic distance to trade partners, and to a lesser extent economic development, are beyond the influence of trade policy. Nevertheless, economic and trade policies are used to influence the activities of multinational firms through

\footnotetext{
${ }^{5}$ Geographic distance is calculated following the great circle formula, which uses latitudes and longitudes of the relevant capital cities.

${ }^{6}$ http://www.cepii.fr/CEPII/en/bdd_modele/presentation.asp?id=6
} 
various channels (Blomstrom and Kokko, 2003), and so these need to be accounted for in the economic analysis. To capture the impact of FDI and trade policies on multinational activity we include the measures of the OECD's FDI Regulatory Restrictiveness Index ${ }^{7}$. The index captures deviations from national treatment in order to identify discrimination against foreign investment and is measured on a 0 -to-1 scale, with 0 representing full openness and 1 prohibition. Hence, we expect a negative coefficient on the FDI regulatory restrictiveness index. The advantage of the OECD's FDI restrictiveness index is that it displays sector-specific levels of restrictiveness and covers important main sectors and several sub-sectors.

Furthermore, to address the discussion on fragmentation and the increased importance of traded services in the fragmentation process we include manufacturing $\mathrm{FDI}^{8}$ in our empirical analysis. This allows us to study the role of services as inputs in the manufacturing process and accounts for indirect exports of services. Thus, we expect a positive relationship between manufacturing FDI and affiliate activity. In addition, given the linkage between manufacturing and services trade, both FDI streams are influenced by investment regulation and policies across modes that need to be considered in the actual policy environment. Summary statistics of the variables included in the regression analysis are reported in Table 1. From the descriptive statistics we can observe that on average the value of affiliates sales is more than twice as high than unaffiliated cross-border trade. With respect to the distance variables, the average distance for service and manufacturing sectors is 6806 kilometers and $40 \%$ of the country pairs share the same language. The overall restrictiveness index is quite low, indicating that there are almost no regulatory impediments to FDI across all sectors. However, comparing service and manufacturing sectors Table 1 reveals that restrictions to FDI are much lower for manufacturing sectors, than services.

\footnotetext{
${ }^{7}$ http://www. oecd.org/investment/fdiindex.htm

${ }^{8}$ Data on manufacturing FDI are taken from the Bureau of Economic Analysis and display U.S. direct investment positions abroad.
} 
Histograms for the affiliate count variable are presented in Figure 1 and Figure 2. In Figure 1 we have the count of affiliates across sector:partner pairs (so all sectors pooled), while in Figure 2 we present sector averages ( 8 broad goods categories and 7 broad service sectors). Summed across all sectors, the number of parents with affiliates in the destination country varies between 0 and 1471, whereby we have 120 cases with zero counts and on average 51 affiliates in the destination country across all sectors. Foreign affiliates are on average 7681 kilometers away from their U.S. multinational parents and a common language is shared in a quarter of all country pairs. In the next section we provide deeper insights into the location choice of U.S. affiliates and the mode of delivery in services.

\section{$3.2 \quad$ U.S. Parents with Foreign Affiliates}

We first examine establishment of foreign affiliates of U.S. parents in services, based on affiliate population counts. As noted above, we focus on distance and market size, as well as the level of openness as determined by policy measures. Using U.S. data on parents having an affiliate abroad we employ a Poisson (PRM) and negative binomial regression model (NBRM), the latter to account for the heterogeneity that results in over-dispersion in the marginal distribution of the count (Long, 1997). Both models can be estimated by maximum likelihood estimation with robust standard errors. As the models are nested, we can compare between the Poisson model and Negative binomial model by testing the dispersion parameter $\alpha$. Estimates of the PRM and NBRM for the number of foreign affiliates are given in Table 2. Since the dispersion parameter $\alpha$ is positive and significant at the $1 \%$ significance level, we find strong evidence for overdispersion. ${ }^{9}$ In our case, the associated chi-squared value of the LR test is 24477 , indicating that alpha is significantly different from zero and thus suggesting that the Negative binomial model is more appropriate than the Poisson

\footnotetext{
${ }^{9}$ If the overdispersion parameter $\alpha$ is zero the NBRM collapses to the Poisson regression model. This can be tested by a one-tailed z-test or a likelihood ratio (LR) test.
} 
model.

The univariate Poisson distribution indicating the number of times the event $y$ is occurring during a fixed interval can be specified by the following probability mass function

$$
\operatorname{Pr}(y \mid \mu)=\frac{e^{-\mu} \mu^{y}}{y !} \text { for } \mathrm{y}=0,1,2, \ldots
$$

The conditional mean depends on the individual characteristics from the structural model and can be formulated as $\mu=E\left(y_{i} \mid x_{i}\right)=\exp \left(x_{i} \beta\right)$, which ensures $\mu$ to be positive. ${ }^{10}$ The estimated $\beta$ 's of the PRM and NBRM can be interpreted in the same way, as the expected value of the count variable $\mathbf{y}$ for a given $\mathbf{x}$ is in both models equal to $\mu=\exp (x \beta)$. In general, the estimates in Table 2 from the two models - PRM versus NBRM - are very robust with respect to the signs of the coefficients and the significance levels. However, as the test on overdispersion prefers the NBRM to the PRM the interpretation of our results will focus on the negative binomial regression model. From the results in Table 2 , distance matters for foreign affiliates as the various distance measures, like geographical distance, sharing a common language and being contiguous, have a positive and significant impact on the number of U.S. foreign affiliates. Regarding geographical distance, our findings suggest that increasing distance by $1 \%$ increases the number of foreign affiliates by $0.434 \% .{ }^{11}$ A common language increases the expected number of foreign affiliates by almost $20 \%$, holding all other variables constant. ${ }^{12}$ For sensitivity analysis we also estimated a Zeroinflated negative binomial model (ZINB) to account for the possibility that the zero counts are generated by a different process than the positive counts (Long, 1997) and the results remain robust for this specification. ${ }^{13}$

\footnotetext{
${ }^{10} \mathbf{x}$ is the matrix of explanatory variables, also comprising indicator variables.

${ }^{11}$ Following Long (1997) we calculated the percentage change in the expected count for a $\delta$ unit change in distance.

${ }^{12}$ By using factor changes the coefficient for language can be interpreted as = $100[\exp (0.182)-1]$ according to Long (1997).

${ }^{13}$ The results from the ZINB model with a binary logit model (where the outcome event is having a zero count) are not reported in the paper, but are available upon request.
} 


\subsection{Outward Shares}

We next turn to the relationship between cross border trade and affiliate sales (selling through a physical presence abroad). As in Brainard (1993, 1997), our dependent variable is affiliate sales as a share of total foreign sales by U.S. firms. Following Papke and Wooldridge (1996), we use GLM-based estimators.

Given that the United States is always the home market, outward shares OUTSH $H_{i t}^{j}$ should reflect how characteristics of the destination markets determine the choice between exporting and affiliate sales. In other words, working from U.S. data, we can isolate destination characteristics. The baseline econometric model can be written as

$$
\operatorname{OUTSH} H_{i t}^{j}=\alpha_{0}+\beta_{\mathbf{1}} \mathbf{X}_{\mathbf{i t}}+\beta_{\mathbf{2}} \mathbf{X}_{\mathbf{i}}+\beta_{\mathbf{3}} \mathbf{X}_{\mathbf{i} \mathbf{j}}+v_{i t}^{j},
$$

where $i, t$ and $j$ index countries, time and service sectors. While vector $\mathbf{X}_{\mathbf{i t}}$ represents time-varying explanatory variables for country i (GDP, similarity index, tax rates, freedom indices, etc.), vector $\mathbf{X}_{\mathbf{i}}$ comprises time invariant explanatory variables for country $\mathrm{i}$ (distance, common language). Vector $\mathbf{X}_{\mathbf{i j}}$ displays sector-varying explanatory variables for country i, like the FDI restrictiveness index. $v_{i t}^{j}$ represents the respective error term.

Table 3 reports the results using OUTSH, the share of outward affiliates sales in total outward sales, as a dependent variable applying a GLM estimator. We find a consistent positive impact of distance on the likelihood of U.S. firms establishing affiliates in foreign countries across all service categories. The results suggest that proximity between consumers and suppliers of services is still needed or desired, so that multinational activity relative to exports increases the further away are destination markets. The impact of FDI restrictions on the share of outward affiliate sales is consistently negative, indicating that discriminatory barriers have a strong interfering aspect on affiliate sales except for legal 
services. The coefficient for common language generally shows the expected sign, although our results also support sector level differences.

While in a first step, we have estimated equation (2) alone using GLM, as a robustness check we also test for linkages between total outward volumes (affiliate sales+cross border sales) and the outward affiliate sales share, estimating both jointly using a seemingly unrelated regression (SUR) estimator. By imposing a joint variance covariance structure this approach takes contemporaneous correlations into account. Table 4 reports these results for the baseline equation. These results support the basic pattern of results reported in Table 3. As in the base case with GLM, our results show a strong impact of distance (though this varies by sector), discriminatory barriers and common language on total sales and on affiliate shares. Moreover, the coefficient on manufacturing FDI supports the previous findings from the literature that manufacturing FDI is intertwined with trade in services, since services are used as inputs in the manufacturing process.

\section{Comparison to Manufacturing}

Fragmentation of production processes in order to increase efficiency and profits has accelerated in manufacturing sectors over the last decade. Technological changes as well as trade and investment liberalisation have helped foster this fragmentation process, which is characterised by increasing complexity and international orientation. Since services are increasingly used in manufacturing processes - as intermediate inputs but also as stand-alone production components - the intertwined linkage between services trade and manufacturing is apparent (Egger et al., 2015). Including manufacturing FDI in our regressions, we find a positive effect of manufacturing FDI on affiliate activity for some service sectors in outward sales, in particular business services (last column of Table 3). Such results support the findings on manufacturing and business ser- 
vices linkages previously found in the economic literature (Francois and Woerz, 2008; Gage and Lesher, 2005; Egger et al., 2015). Going one step further, we aim here at identifying whether patterns of affiliate intensity are similar between manufacturing and service sectors. Along similar lines, Riedl (2008) contrasts the dynamic patterns of manufacturing and service FDI in transition countries using the data from the wiiw database on Foreign Direct Investment.

We apply the same econometric specification as in Section 3, comparing determinants in manufacturing sectors to drivers of affiliate activity in service sectors. As discussed in the introduction, because of the nature of service transactions, which favour proximity between supplier and consumer, we expected a consistent positive impact of distance on outward affiliate shares. In contrast, we are more agnostic on goods, as we may expect manufacturing FDI to take place between countries located next to each other in order to exploit agglomeration advantages. Moreover, manufacturing services may be relatively more affected by efficiency motives, rather than market seeking motives. Using the share of outward affiliate sales in total outward sales, we again employ a GLM estimator.

Results for the outward affiliate sales share in manufacturing are presented in Table 5 . For total manufactures, Table 5 shows a reversed impact of distance on affiliate intensity compared to most of our service sectors. In contrast to our results found in service sectors, affiliate sales intensity decreases the further away are host countries for total sales in manufacturing. However, the results vary at sector level. For transport equipment, electrical equipment, computers (and metals though not significant) distance has a negative impact on affiliate intensity, while the opposite is the case for chemicals and other machinery. With the exception of processed foods, sales to larger economies are also more affiliate intensive. For comparison, this also holds for finance, insurance, computer, and legal services but not for other sectors in Table 3. Like our service results, the pattern with respect to income levels is mixed across sectors. For 
some sectors (food, metals, other machinery, and transport equipment) sales in lower income countries are more affiliate intensive. Where significant, the impact of FDI restrictions shows the predicted negative sign, except for computers and electrical equipment. However, this is not so surprising as manufacturing sectors are relatively less restricted in terms of FDI. To test whether manufacturing FDI is influenced by services transactions, we have also included services value added in \% of GDP in our specification. Our results support the intertwined linkages between services and manufacturing transactions, as services value added significantly raises affiliate activity in manufacturing sectors.

\section{Summary and closing comments}

In this paper we focus on the choice of modes of delivery in services based on data for U.S. cross border sales and sales through affiliates. We examine the decision of firms to establish affiliates in particular markets, and also the relationship between direct cross-border trade and indirect sales through affiliates as alternative modes of delivery. In terms of the population of affiliates, we find that larger markets and higher income markets, but also more distant markets, attract larger numbers of U.S. affiliates. At the industry level, the importance of proximity between supplier and consumer, what we call the proximity burden, appears empirically robust in explaining increased affiliate activity relative to cross-border sales with increased distance for communications, business services, legal services, consulting services, advertising, and R\&D. Multinational activity in services (sales through affiliates) increases relative to direct exports in these sectors the further away are host countries, the lower are investment barriers and the higher is manufacturing FDI. For manufacturing firms, depending on the sector, the impact of key factors identified here differ in important ways between goods and services sectors, mainly with respect to distance and the underlying proximity burden for services trade. 
Given relatively high degrees of concentration (and so low numbers of firms going into particular markets), the importance of size and distance in the entry decision, our results suggest that core factors to emphasise in developing a full analytical picture for trade and FDI in services may vary in important ways from the relevant set of factors for goods, and indeed may vary across service sectors themselves. 


\section{References}

Bekkers, E., Francois, J., 2013. Trade and industrial structure with large firms and heterogeneity. European Economic Review 80, 69 - 90.

Blomstrom, M., Kokko, A., 2003. The economics of foreign direct investment incentives. NBER Working Paper No. 9489.

Brainard, S. L., 1993. A simple theory of multinational corporations and trade with a trade-off between proximity and concentration. NBER Working Paper No. 4269 .

Brainard, S. L., 1997. An empirical assessment of the proximity-concentration trade-off between multinational sales and trade. American Economic Review $87,520-544$.

Breinlich, H., Criscuolo, C., 2011. International trade in services: A portrait of importers and exporters. Journal of International Economics 84 (2), 188-206.

Cameron, C., Trivedi, P., 1986. Econometric models based on count data: Comparisons and applications of some estimators and tests. Journal of Applied Econometrics 1, 29-53.

Christen, E., Francois, J., 2010. Modes of delivery in services. Department of Economics, Johannes Kepler University Linz. Working Paper No. 1008.

Egger, P., Francois, J., Nelson, D., 2015. The role of goods trade networks for services trade volume. The World Economy, forthcoming.

Francois, J., Hoekman, B., 2010. Services trade and policy. Journal of Economic Literature 483 (3), 642-692.

Francois, J. F., Woerz, J., 2008. Producer services, manufacturing linkages, and trade. Journal of Industry, Competition and Trade 8 (3), 199-229.

Gage, J., Lesher, M., 2005. Intertwined: FDI in manufacturing and trade in services. OECD Trade Policy Working Papers No. 25.

Grim, A., Krishnan, C., 2014. U.S. international services: Cross-border trade in 2013 and services supplied through affiliates in 2012. Survey of Current Business October, 1-25.

Helpman, E., Melitz, M. J., Yeaple, S. R., 2004. Export versus FDI. American Economic Review 94 (1), 300-316.

Kelle, M., 2013. Crossborder and foreign affiliate sales of services: Evidence from German microdata. The World Economy 36 (11), 1373-1392.

Long, S., 1997. Regression Models for Categorial and Limited Dependent Variables. SAGE Publications Inc., California.

Mayer, T., Zignago, S., 2011. Notes on CEPII's distances measures. CEPII Working Paper 2011-25, Paris. 
Melitz, M. J., 2003. The impact of trade on intra-industry reallocations and aggregate industry productivity. Econometrica 71 (6), 1695-1725.

Papke, L. E., Wooldridge, J. M., 1996. Econometric methods for fractional response variables with an application to $401(\mathrm{k})$ plan participation rates. Journal of Applied Econometrics 11 (6), 619-632.

Riedl, A., 2008. Contrasting the dynamic patterns of manufacturing and service FDI: Evidence from transition economies. Department of Economics, Vienna University of Economics B.A.. Working Paper No. 117.

Sampson, G. P., Snape, R. H., 1985. Identifying th issues in trade in services. The World Economy 8, 171-182. 


\section{A Appendix}

Table 1: Descriptive Statistics

\begin{tabular}{|c|c|c|c|c|c|}
\hline Variable & Obs & Mean & Std. Dev. & Min & Max \\
\hline \multicolumn{6}{|c|}{ Service sectors } \\
\hline Outward sales share & 559 & 0.704 & 0.258 & 0 & 0.994 \\
\hline Affiliate sales & 652 & 1616.842 & 3307.310 & 0 & 24420 \\
\hline Cross-border trade & 1407 & 658.277 & 1411.569 & 3 & 15867 \\
\hline Distance & 1590 & 6805.812 & 3964.531 & 548.395 & 16008.790 \\
\hline Log Distance & 1590 & 8.577 & 0.854 & 6.307 & 9.681 \\
\hline GDP partner & 1590 & 1349.747 & 1190.450 & 249.919 & 4667.450 \\
\hline Log GDP & 1590 & 6.865 & 0.818 & 5.521 & 8.448 \\
\hline GDP per capita & 1590 & 22222.750 & 10151.670 & 3594.785 & 39771.950 \\
\hline Log GDP pc. & 1590 & 9.822 & 0.719 & 8.187 & 10.591 \\
\hline Common language & 1590 & 0.400 & 0.490 & 0 & 1 \\
\hline Restrictiveness Index & 1300 & 0.113 & 0.110 & 0 & 0.600 \\
\hline Manufacturing FDI & 1270 & 24460.750 & 18661.560 & 3423 & 83980 \\
\hline Log Manufacturing FDI & 1270 & 9.864 & 0.688 & 8.138 & 11.338 \\
\hline Total outward sales & 559 & 2157.433 & 4004.038 & 44 & 29439 \\
\hline Log Total outward sales & 559 & 6.771 & 1.317 & 3.784 & 10.290 \\
\hline Log Outward share & 554 & 1.173 & 1.609 & -5.204 & 5.086 \\
\hline \multicolumn{6}{|c|}{ Manufacturing sectors } \\
\hline Outward sales share & 456 & 0.532 & 0.444 & 0 & 0.999 \\
\hline Affiliate sales & 456 & 211.665 & 593.526 & 0 & 4662 \\
\hline Cross-border trade & 900 & 10.613 & 20.160 & 0.070 & 162.950 \\
\hline Distance & 900 & 6805.812 & 3965.487 & 548.395 & 16008.790 \\
\hline Log Distance & 900 & 8.577 & 0.854 & 6.307 & 9.681 \\
\hline GDP partner & 900 & 1312.186 & 1184.406 & 249.919 & 4667.450 \\
\hline Log GDP & 900 & 6.830 & 0.821 & 5.521 & 8.448 \\
\hline GDP per capita & 900 & 22039.450 & 10069.020 & 3594.785 & 38971.840 \\
\hline Log GDP pc. & 900 & 9.814 & 0.719 & 8.187 & 10.571 \\
\hline Common language & 900 & 0.400 & 0.490 & 0 & 1 \\
\hline Restrictiveness Index & 720 & 0.058 & 0.068 & 0 & 0.333 \\
\hline Services value added & 900 & 69.527 & 3.456 & 62.077 & 76.916 \\
\hline \multicolumn{6}{|c|}{ Number of U.S. Parents with foreign affiliates } \\
\hline No. Parents with Affiliates & 1904 & 51.203 & 119.311 & 0 & 1471 \\
\hline Distance & 1904 & 7861.199 & 3849.013 & 548.395 & 16180.320 \\
\hline Log Distance & 1904 & 8.820 & 0.615 & 6.307 & 9.692 \\
\hline Common language & 1904 & 0.250 & 0.433 & 0 & 1 \\
\hline Contiguity & 1904 & 0.036 & 0.186 & 0 & 1 \\
\hline Landlocked & 1904 & 0.089 & 0.285 & 0 & 1 \\
\hline RTA & 1904 & 0.054 & 0.225 & 0 & 1 \\
\hline EU dummy & 1904 & 0.321 & 0.467 & 0 & 1 \\
\hline
\end{tabular}


Table 2: Regression results: Number of parents with foreign affiliates

\begin{tabular}{lcccc}
\hline \hline & \multicolumn{2}{c}{ Services + Manufacturing } & Services & Manufacturing \\
& Poisson & NBRM & NBRM & NBRM \\
\hline Log Distance & $0.106^{*}$ & $0.434^{* * *}$ & $0.343^{* * *}$ & $0.531^{* * *}$ \\
& $(0.058)$ & $(0.056)$ & $(0.080)$ & $(0.054)$ \\
Log GDP & $0.263^{* * *}$ & $0.104^{* * *}$ & $0.087^{* * *}$ & $0.115^{* * *}$ \\
& $(0.053)$ & $(0.011)$ & $(0.015)$ & $(0.015)$ \\
Log GDP pc. & $0.184^{* * *}$ & $0.235^{* * *}$ & $0.369^{* * *}$ & $0.145^{* * *}$ \\
& $(0.028)$ & $(0.019)$ & $(0.027)$ & $(0.023)$ \\
Language & $0.394^{* * *}$ & $0.182^{* * *}$ & $0.321^{* * *}$ & 0.081 \\
& $(0.052)$ & $(0.049)$ & $(0.073)$ & $(0.060)$ \\
Contiguity & $0.794^{* * *}$ & $2.010^{* * *}$ & $1.459^{* * *}$ & $2.426^{* * *}$ \\
& $(0.251)$ & $(0.176)$ & $(0.215)$ & $(0.223)$ \\
Landlocked & $-0.286^{* * *}$ & $-0.510^{* * *}$ & $-0.327^{* * *}$ & $-0.664^{* * *}$ \\
RTA & $(0.108)$ & $(0.064)$ & $(0.089)$ & $(0.079)$ \\
EU & $0.290^{* * *}$ & -0.024 & 0.019 & -0.015 \\
& $(0.098)$ & $(0.085)$ & $(0.078)$ & $(0.134)$ \\
Constant & $0.312^{* * *}$ & $0.348^{* * *}$ & $0.258^{* * *}$ & $0.456^{* * *}$ \\
& $(0.059)$ & $(0.055)$ & $(0.079)$ & $(0.064)$ \\
& $-3.909^{* * *}$ & $-3.100^{* * *}$ & $-4.438^{* * *}$ & $-3.421^{* * *}$ \\
Observations & $(0.817)$ & $(0.532)$ & $(0.754)$ & $(0.557)$ \\
lnalpha & 1,904 & 1,904 & 672 & 1,232 \\
Log Likelihood & -19789 & -7551 & -2802 & $-0.439^{* * *}$ \\
\hline \hline
\end{tabular}

Notes: Estimates based on equation 1. Dependent variable is number of U.S. parents with foreign affiliates. Estimation method: Negative binomial regression model (NBRM) and Poisson regression model (PRM). Robust standard errors are reported in parentheses. Sector and year dummy variables are included in the specification, but are not reported in the table. *, ** and *** indicate statistical significance at the 10-percent level, 5-percent level, and 1-percent level. 
Figure 1: The distribution of the number of U.S. parents with foreign affiliates in goods and services sectors by sector-country pairs
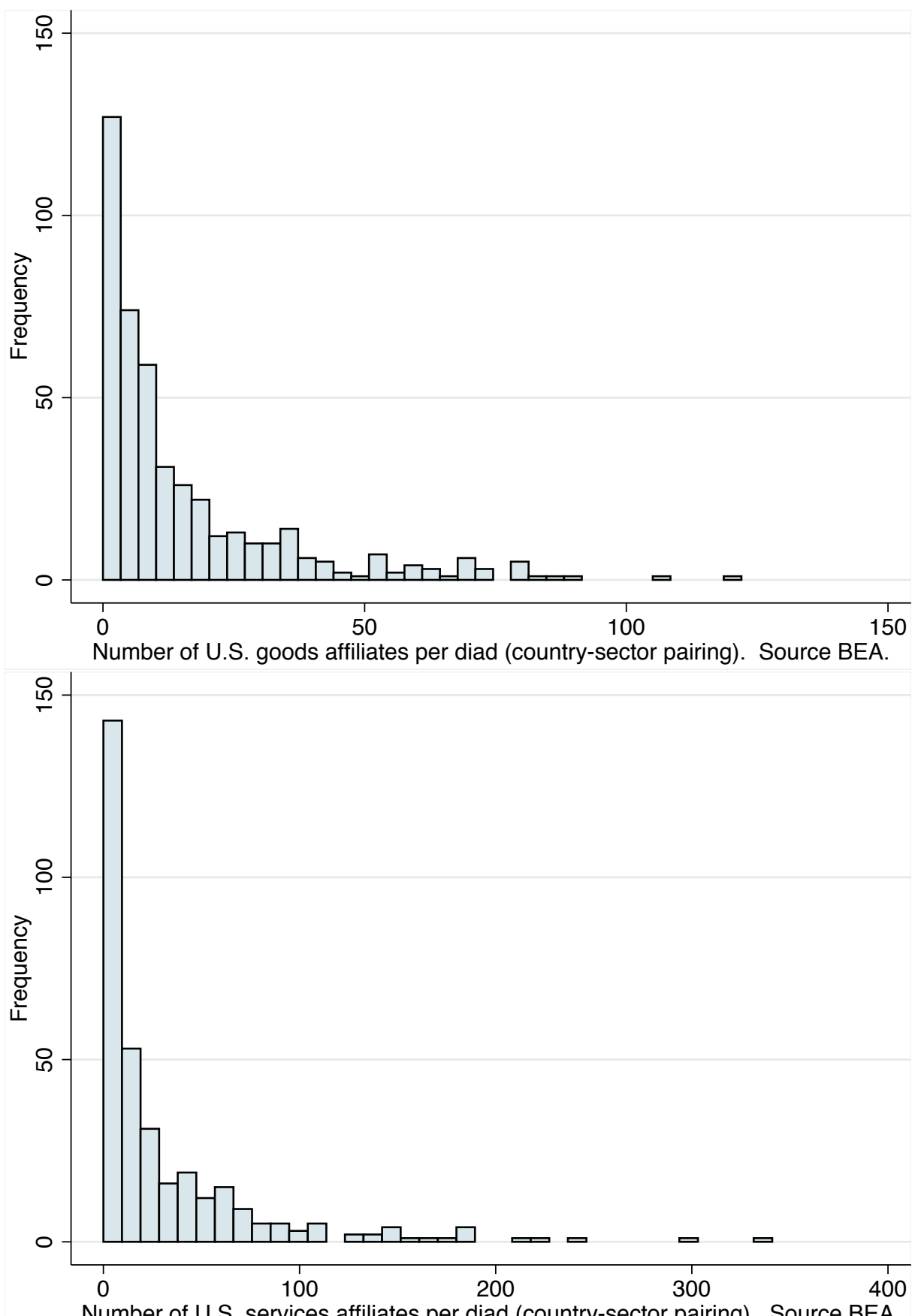
Figure 2: The average number of U.S. parents with foreign affiliates by sector
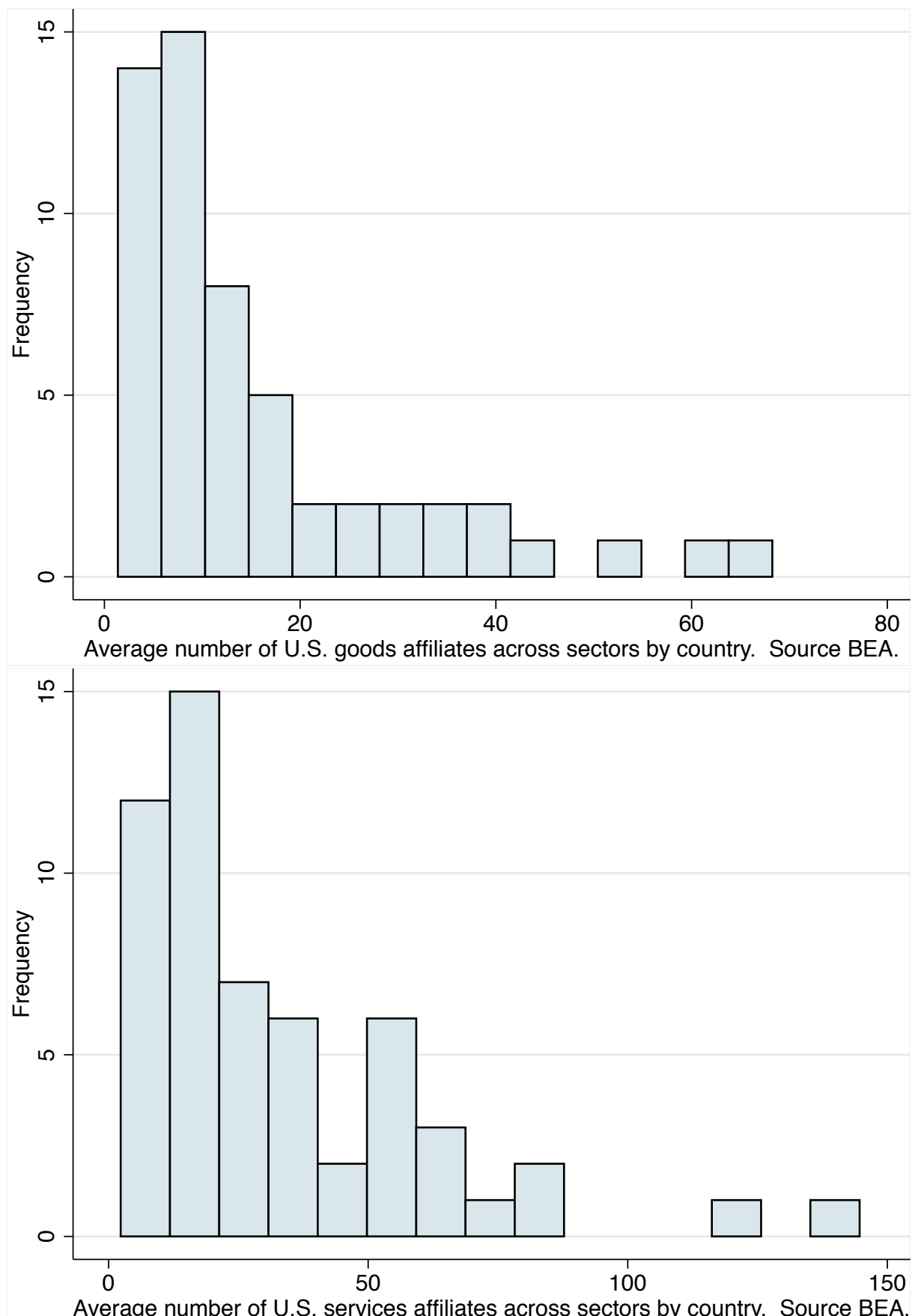


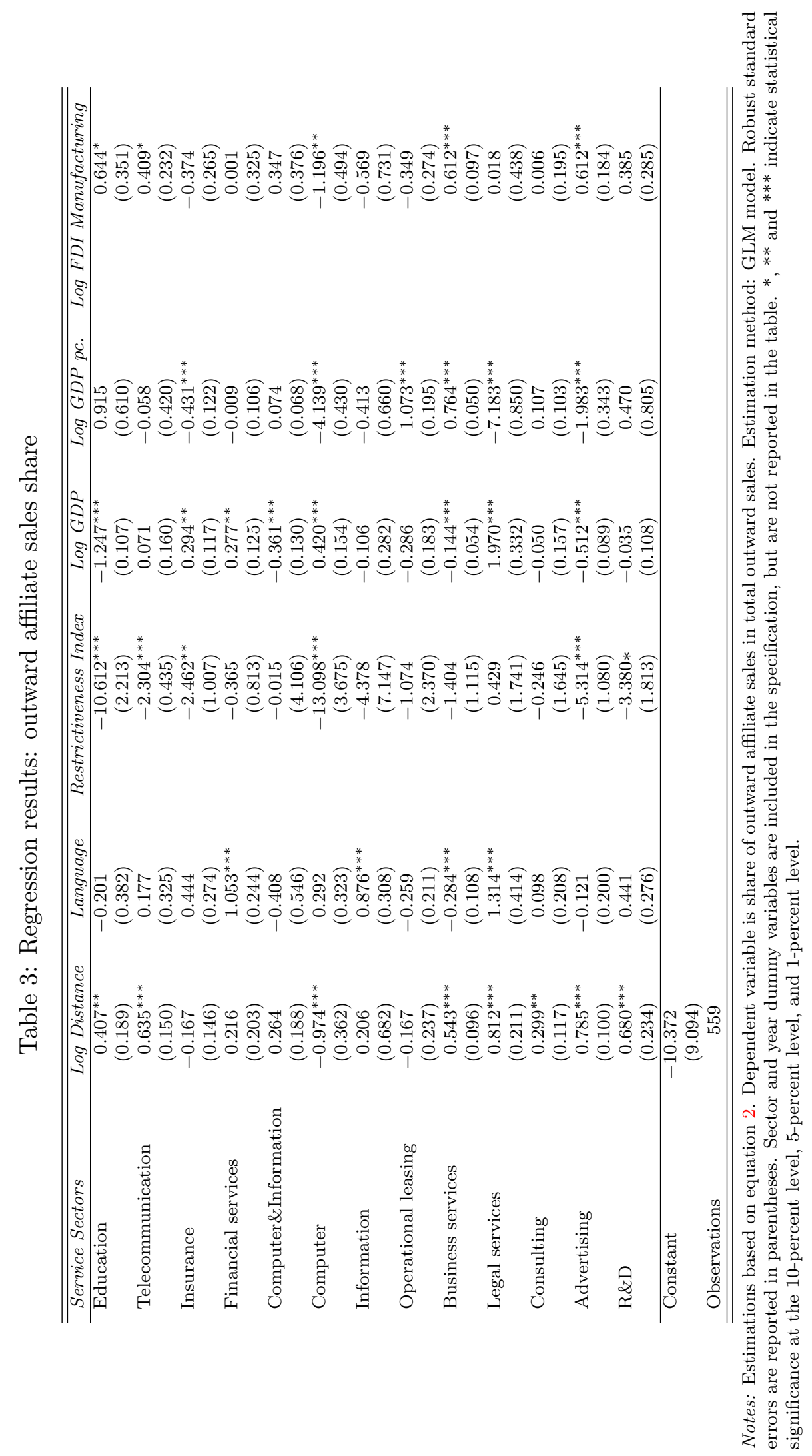




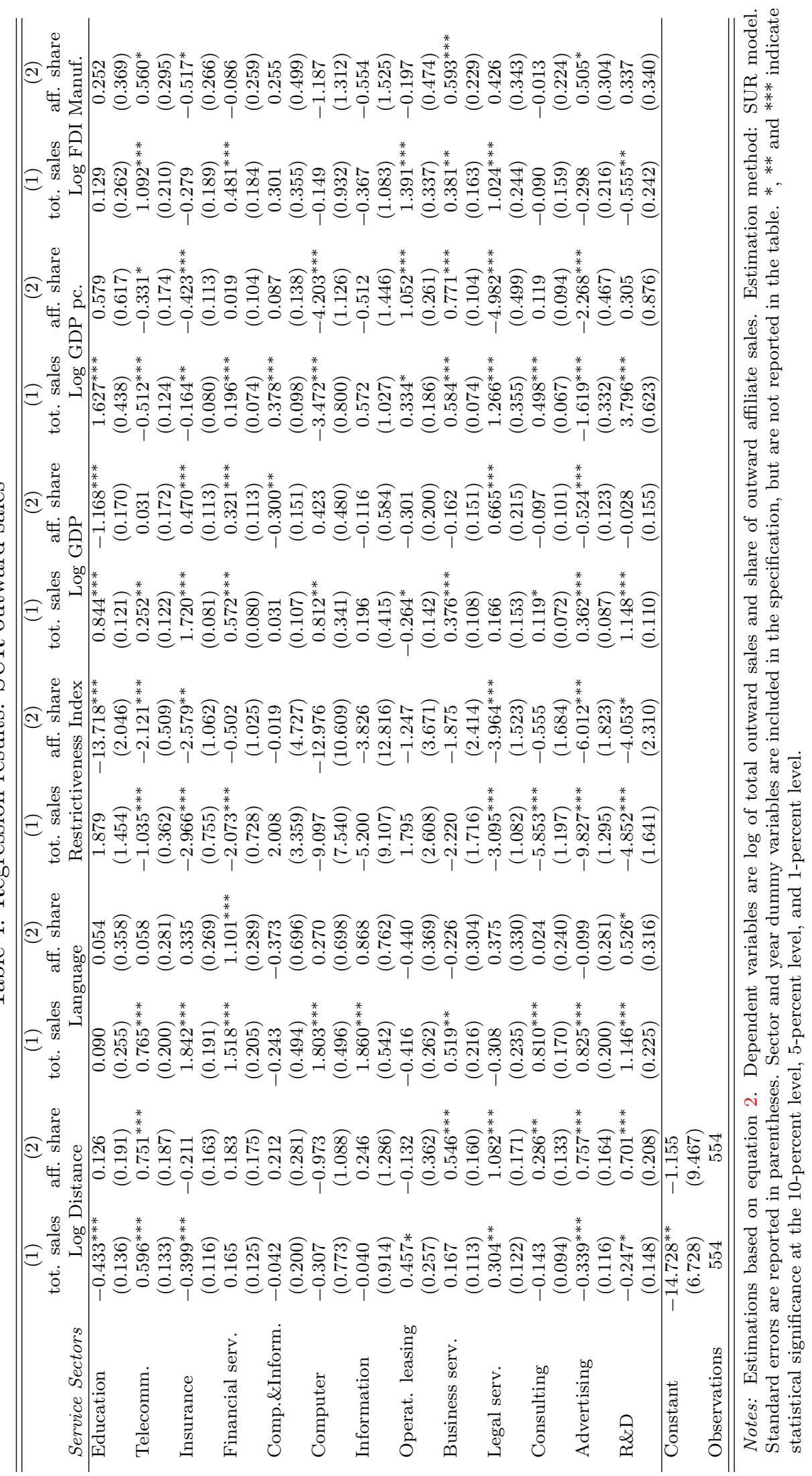




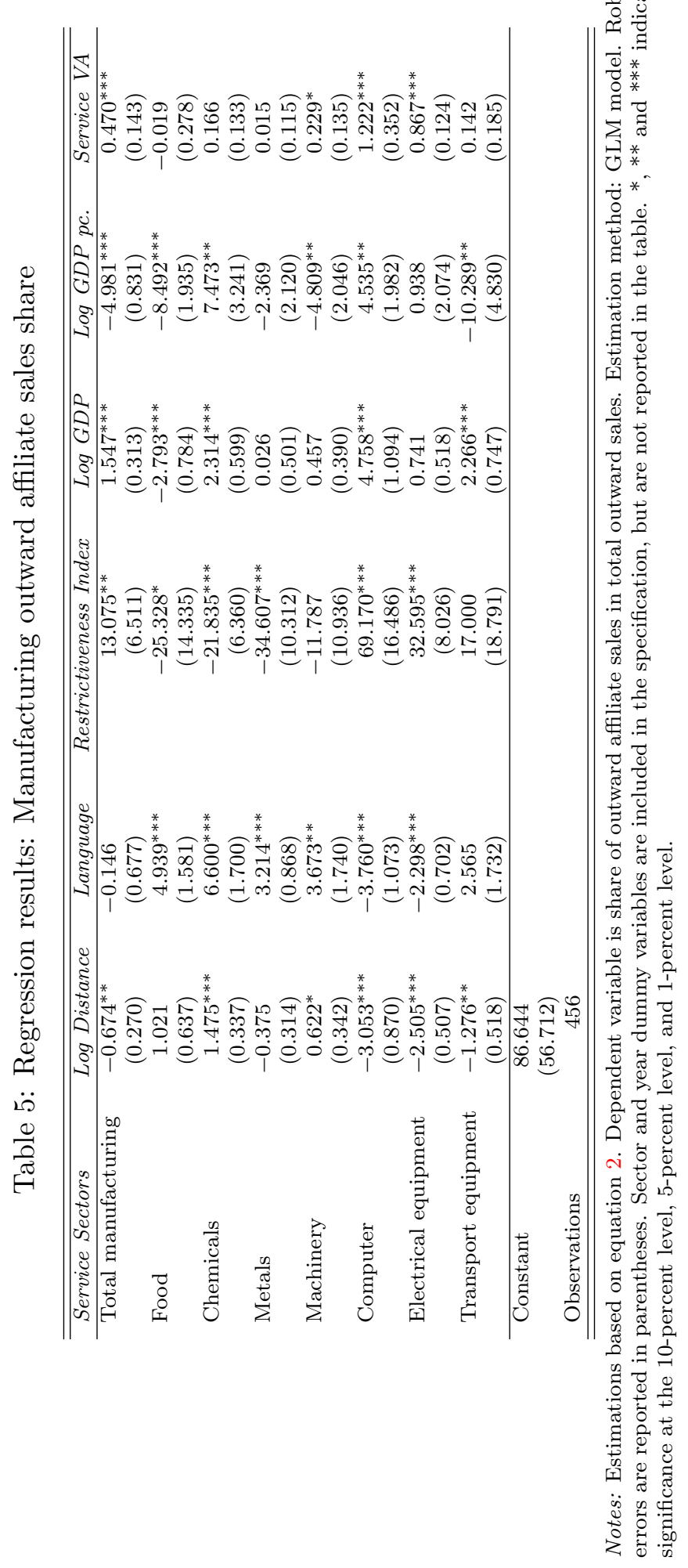

